Research Article

\title{
Sustainable High-Ductility Concrete with Rapid Self-Healing Characteristic by Adding Magnesium Oxide and Superabsorbent Polymer
}

\author{
Shuyin Wu ${ }^{D},{ }^{1}$ Guoyang Lu, ${ }^{2}$ Quan Liu $\left(\mathbb{D},{ }^{2}\right.$ Pengfei Liu $\mathbb{D}^{2},{ }^{2}$ and Jun Yang ${ }^{1}{ }^{1}$ \\ ${ }^{1}$ School of Transportation, Southeast University, Nanjing 211189, China \\ ${ }^{2}$ Institute of Highway Engineering, RWTH Aachen University, Aachen D52074, Germany \\ Correspondence should be addressed to Jun Yang; 220183058@seu.edu.cn
}

Received 14 October 2019; Revised 11 December 2019; Accepted 24 December 2019; Published 22 January 2020

Academic Editor: Sakar Mohan

Copyright (c) 2020 Shuyin Wu et al. This is an open access article distributed under the Creative Commons Attribution License, which permits unrestricted use, distribution, and reproduction in any medium, provided the original work is properly cited.

As a class of high-ductility concrete, engineered cementitious composites (ECC) have wide application prospects in engineering fields. However, the occurrence of cracks and the limited self-healing ability hinder the development of ECC. Rapid self-healing has important significance for ECC in reducing maintenance costs and prolonging service life, which are conducive to sustainable development of ECC. Therefore, the aim of this paper is to enhance the self-healing property of ECC by adding light-burned magnesium oxide $(\mathrm{MgO})$ and superabsorbent polymer (SAP) on the premise of maintaining the high ductility. First, the effect of $\mathrm{MgO}$ and SAP on the ductility property of ECC which is the most important feature was explored with the uniaxial tensile test. The results indicated that $\mathrm{MgO}$ is helpful to the strength but not conducive to the ductility of ECC, while SAP has an opposite effect. The effects of $\mathrm{MgO}$ and SAP on the ductility of ECC can be balanced. Later, the permeability test, scanning electron microscopy (SEM), and X-ray diffraction (XRD) were used to evaluate the effects of $\mathrm{MgO}$ and SAP on the self-healing property of ECC. The results showed that the combined addition of $\mathrm{MgO}$ and $\mathrm{SAP}$ shows much better effect than the individual addition and can cut the healing time by half. Overall, it is concluded that ECC with $\mathrm{MgO}$ and SAP have the potential for self-healing, and the ductility can also be reconciled.

\section{Introduction}

Engineered cementitious composites (ECC) are a typical kind of high-ductility cementitious composites (HDCC). The ultimate tensile strain of ECC can be above 3\%, which is 300 times larger than that of the ordinary cement concrete, and the crack width in a saturated state is below $100 \mu \mathrm{m}[1-3]$. Since the successful preparation of ECC, many scholars have carried out the engineering applications of ECC, such as highway bridge link slab, steel deck pavement, and ECC-concrete composite beam, retrofitting of structures in seismic regions [4-9]. The good mechanical properties and simple construction technology make ECC suitable for practical engineering projects. However, ECC is considerably affected by loading and environmental factors. Cracks may occur in ECC due to the action of loading and environment, which not only weaken the mechanical properties but also cause moisture damage.

The unhydrated or insufficiently hydrated materials at the damaged part of cement-based materials tend to hydrate further and produce products to heal a crack, which is known as self-healing behavior [10]. Huang et al. [11] pointed out that the early self-healing of cement-based materials is mainly realized by hydration of unhydrated cement. Lauer and Slate [12] investigated the effect of humidity on the self-healing behavior of cement-based materials and found that $95 \%$ relative humidity induces the fastest self-healing rate. Dhir et al. [13] showed that the rate of self-healing decreases with the increase of age. Fang et al. [14] concluded that $\mathrm{Ca}^{2+}$ distributed in cement-based materials and $\mathrm{CO}_{3}{ }^{2-}$ dissolved in water form $\mathrm{CaCO}_{3}$ crystals, which conduce to crack self-healing of cement- 
based materials. Edvardsen [15] found that the increasing rate of $\mathrm{CaCO}_{3}$ crystals at cracks is related to crack width and water pressure. However, the material composition, age, temperature, humidity, crack width, and others have significant effects on the property of self-healing. In general, the crack width of ordinary cement-based materials is relatively large, and limited self-healing products are incapable of efficiently repairing those cracks.

ECC material is found to have more potential for selfhealing than ordinary cementitious composites. Maalej et al. [16] proposed that ECC produces fine cracks under load, which is conducive to the self-healing of cracks. Kan et al. [17] pointed out that polyvinyl alcohol (PVA) fibers in ECC have hydrophilic properties, which provide nucleation points for the formation of self-healing products and help the formation and growth of self-healing products. But, for ECC entity engineering, the environmental temperature and humidity conditions are difficult to be adjusted; hence, it is of difficulty to achieve complete self-healing for ECC. The achievement of rapid self-healing for ECC in the natural environment has important theoretical and practical significance in reducing maintenance costs and prolonging service life. Many researchers have explored the self-healing properties of ECC through theoretical and experimental methods [18-25]. The common method used in the literature to accelerate the self-healing of ECC is adding the supplementary cementitious materials (SCM) [23]. But, the effects are not completely satisfactory and quite different among the studies. Therefore, it is also necessary to find a faster and better self-healing method for ECC.

Magnesium oxide ( $\mathrm{MgO}$ ) has been used as an expansion additive in mass concrete [20]. Addition of $\mathrm{MgO}$ into mass concrete makes the concrete possess microexpansion characteristics. The shrinkage of concrete, especially the temperature shrinkage, can be compensated and the crack resistance of concrete can be improved. The microexpansion feature of $\mathrm{MgO}$ is beneficial to crack closure and has great potential in the self-healing of cementitious materials. However, there are limited studies focusing on this.

Superabsorbent polymer (SAP) is used as curing additives in concrete [18]. SAP particles can provide plenty of water due to their ability to serve as a water reservoir. It has a three-dimensional cross-linked network structure, which can fix water inside the polymer network by swelling action. It has good water retention even under pressure and can release water slowly in dry air. As a novel self-healing technique, SAP can also be used in ECC as a self-healing agent to serve as internal water curing.

In this paper, light-burned $\mathrm{MgO}$ and SAP were added in ECC to enhance its self-healing property. In general, a strong chemical bonding between the polyvinyl alcohol (PVA) fiber and cement hydrates restricts the achievement of high ductility for ECC. The fly ash which is the waste produced during the production process of a thermal power plant can improve the interfacial behavior between the matrix and PVA fibers, and this is very helpful to the ductility [26-28]. Therefore, ECC in this paper were prepared with a high volume of fly ash. Due to that the ductility is the most important property for ECC, the effects of $\mathrm{MgO}$ and SAP on the ductility of ECC were first studied with the uniaxial tensile test. The self-healing mechanism of ECC incorporating $\mathrm{MgO}$ and SAP was investigated using the permeability test, scanning electron microscopy (SEM), and X-ray diffraction (XRD). The self-healing method for ECC proposed in this paper can improve its function, prolong its life, and reduce its maintenance cost, which is really conducive to sustainable development of ECC.

\section{Materials and Experiments}

2.1. Raw Materials. The raw materials used in this study were cement, fly ash, quartz sand, PVA fiber, water, water reducer, $\mathrm{SAP}$, and light-burned $\mathrm{MgO}$. The chemical composition of cement and fly ash is shown in Table 1. The particle size of quartz sand is 70-140 mesh. The $\mathrm{SiO}_{2}$ content of quartz sand is $98.7 \%$, and its density is $2.66 \mathrm{~g} / \mathrm{cm}^{3}$. The properties of PVA fiber are shown in Table 2.

Light-burned $\mathrm{MgO}$ has high activity and good volume stability. $\mathrm{MgO}$ used in this paper was produced by burning raw $\mathrm{MgCO}_{3}$. The calcination temperature was $900^{\circ} \mathrm{C}$, and the holding time was $2 \mathrm{~h}$. The main properties of light-burned $\mathrm{MgO}$ are shown in Table 3.

SAP has a three-dimensional cross-linked network structure, and it can absorb and release water repeatedly. The main properties of SAP used in this paper are shown in Table 4.

The contents of $\mathrm{MgO}$ and SAP directly affect the performance of ECC. Superfluous $\mathrm{MgO}$ will cause excessive expansion, which may lead to the destruction of the internal structure of ECC, while a small quantity of $\mathrm{MgO}$ cannot satisfy the expected expansion effect. On the contrary, the suitable amount of SAP promotes the hydration of cementitious material and is conducive to the strength development of the composites, but the excessive amount of SAP produces many honeycomb-like voids after the loss of water, which affects the strength of the composites. According to the relevant researches [18-20] and the preliminary tests, the mix proportions of ECC used in this study are shown in Table 5.

The mixing procedure for ECC was as follows: (1) cement, fly ash, MgO, SAP, and silica sand were added into a blender and mixed at $100 \mathrm{rpm}$ for $3 \mathrm{~min}$. (2) Water and water reducer which were previously dissolved in water were added and mixed at $100 \mathrm{rpm}$ for $1 \mathrm{~min}$ and then $400 \mathrm{rpm}$ for $4 \mathrm{~min}$. (3) Fibers were added slowly and manually along the stirring direction and mixed at $400 \mathrm{rpm}$ for $10 \mathrm{~min}$. The ECC specimens were then kept in a standard curing box at a relative humidity of $(95 \pm 5) \%$ and a temperature of $(20 \pm 2)^{\circ} \mathrm{C}$ for $28 \mathrm{~d}$.

2.2. Uniaxial Tensile Test. The uniaxial tensile test was conducted to evaluate the ductility performance of ECC, as shown in Figure 1. The sizes of tensile specimen were as follows: the total length was $330 \mathrm{~mm}$, the gauge was $80 \mathrm{~mm}$, the width was $60 \mathrm{~mm}$, the narrow width was $30 \mathrm{~mm}$, and the thickness was $13 \mathrm{~mm}$ [21]. The loading rate in the tensile test was $0.5 \mathrm{~mm} / \mathrm{min}$. The force and displacement were automatically collected by the universal testing machine. 
TABle 1: Chemical composition of Portland cement and fly ash.

\begin{tabular}{lcccccccccc}
\hline \multirow{2}{*}{ Material } & \multicolumn{1}{c}{ Chemical component (by weight (\%)) } \\
& $\mathrm{SiO}_{2}$ & $\mathrm{CaO}$ & $\mathrm{Al}_{2} \mathrm{O}_{3}$ & $\mathrm{Fe}_{2} \mathrm{O}_{3}$ & $\mathrm{SO}_{3}$ & $\mathrm{P}_{2} \mathrm{O}_{5}$ & $\mathrm{~K}_{2} \mathrm{O}$ & $\mathrm{Na}_{2} \mathrm{O}$ & $\mathrm{TiO}_{2}$ & $\mathrm{MgO}$ \\
\hline Cement & 21.26 & 57.82 & 7.67 & 2.88 & 4.04 & 5.26 & 0.78 & - & 0.21 & - \\
Fly ash & 56.18 & 2.82 & 31.46 & 3.85 & 0.69 & 0.91 & - & 1.32 & - \\
\hline
\end{tabular}

TABle 2: Physical and mechanical properties of the PAV fiber.

\begin{tabular}{lccccc}
\hline Diameter $(\mu \mathrm{m})$ & Length $(\mathrm{mm})$ & Elongation $(\%)$ & Density $\left(\mathrm{g} / \mathrm{cm}^{3}\right)$ & Elastic modulus $(\mathrm{GPa})$ & Tensile strength $(\mathrm{MPa})$ \\
\hline 35 & 12 & 7.3 & 1.3 & 31.3 & 1287 \\
\hline
\end{tabular}

TABle 3: Properties of MgO.

\begin{tabular}{lcccc}
\hline $\mathrm{MgO}$ content $(\%)$ & $\mathrm{f}-\mathrm{CaO}$ content $(\%)$ & Loss of ignition (\%) & Water content (\%) & Activity degree (s) \\
\hline$\geq 85.0$ & $\leq 2.0$ & $\leq 4.0$ & $\leq 1.0$ & $50-300$ \\
\hline
\end{tabular}

TABle 4: Properties of SAP.

\begin{tabular}{lccc}
\hline Particle size (mesh size) & Density $\left(\mathrm{g} / \mathrm{cm}^{3}\right)$ & Water absorption $(\mathrm{g} / \mathrm{g})$ & Water absorption speed $(\mathrm{s})$ \\
\hline $30-80$ & 0.8 & $250-600$ & 30 \\
\hline
\end{tabular}

TABle 5: Mix proportions (weight ratio).

\begin{tabular}{lccccccrr}
\hline Group & Cement & Fly ash & Water & Sand & Fiber $^{1}(\%)$ & MgO $^{2}(\%)$ & SAP $^{2}$ & Water reducer $^{2}$ \\
\hline $1 \#$ & 1.00 & 3.00 & 1.20 & 1.44 & 2.00 & - & - & 0.02 \\
$2 \#$ & 1.00 & 3.00 & 1.20 & 1.44 & 2.00 & 6.00 & - & 0.02 \\
$3 \#$ & 1.00 & 3.00 & 1.20 & 1.44 & 2.00 & - & 0.40 & 0.02 \\
$4 \#$ & 1.00 & 3.00 & 1.20 & 1.44 & 2.00 & 6.00 & 0.40 & 0.02 \\
\hline
\end{tabular}

${ }^{1}$ Fiber content is the volume ratio to composites. ${ }^{2}$ Contents of $\mathrm{MgO}$ and SAP, and water reducer is the mass ratio to cement and fly ash.

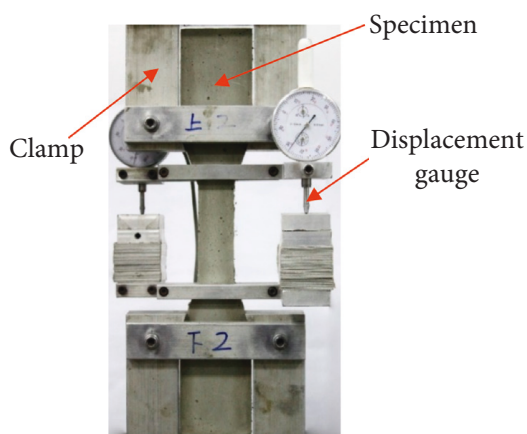

(a)

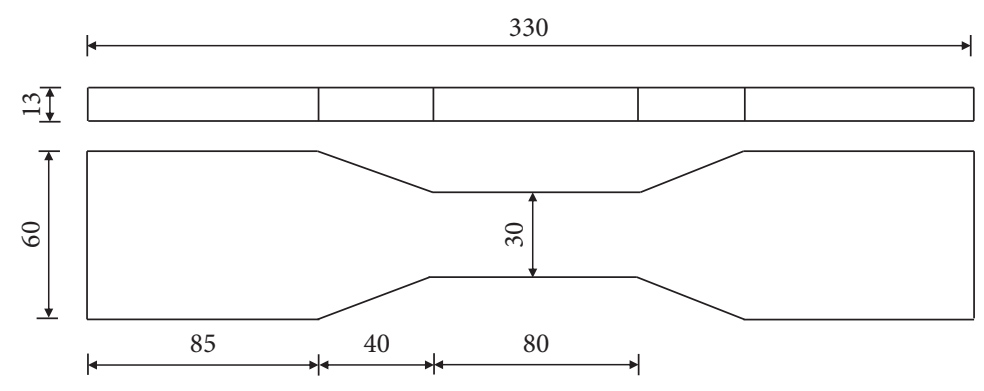

(b)

FIgURE 1: Uniaxial tensile test: (a) test setup; (b) dimensions of the specimen (unit: $\mathrm{mm}$ ).

2.3. Permeability Test. ECC have effective self-healing behavior in the maintenance environment of dry-wet cycles $[22,23]$. Therefore, the self-healing of ECC in this study is achieved by dry-wet cycles. A dry-wet cycle includes immersion in water for $24 \mathrm{~h}$ and then in air for $24 \mathrm{~h}$. The water permeability of ECC will decrease as the cracks heal. Therefore, the permeability test can be used to evaluation the self-healing of ECC $[24,25]$. The relative seepage ratio (RSR) is defined as an evaluation index for self-healing and can be calculated with equation (1). The smaller the value of RSR is, the higher the degree of self-healing of ECC is.

$$
\text { Relative seepage ratio }(\mathrm{RSR})=\frac{V_{N}}{V_{\text {original }}},
$$

where $V_{N}$ is the seepage volume after $N$ dry-wet cycles and $V_{\text {original }}$ is the seepage volume before dry-wet cycles.

The test process was as follows: (1) the specimens with a diameter of $100 \mathrm{~mm}$ and a height of $20 \mathrm{~mm}$ were prepared and preloaded by splitting to produce microcracks [24]; (2) the permeability test was conducted with a water pressure of $0.2 \mathrm{MPa}$ for $60 \mathrm{~min}$. The devices of permeability test are shown in Figure 2. 


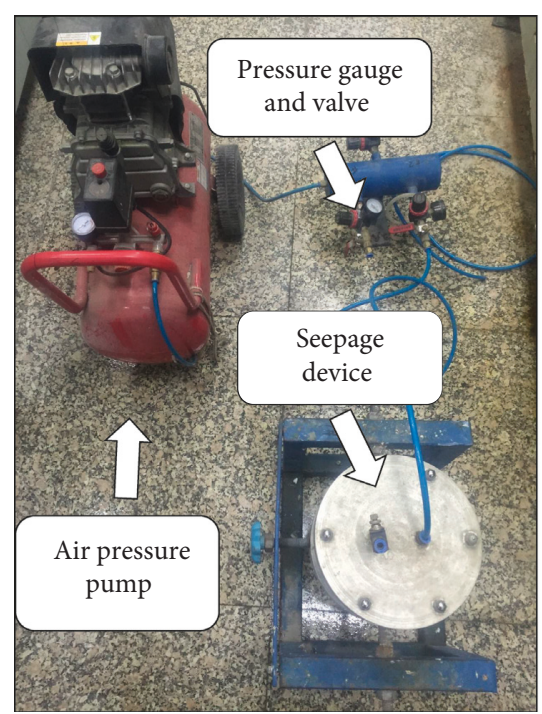

(a)

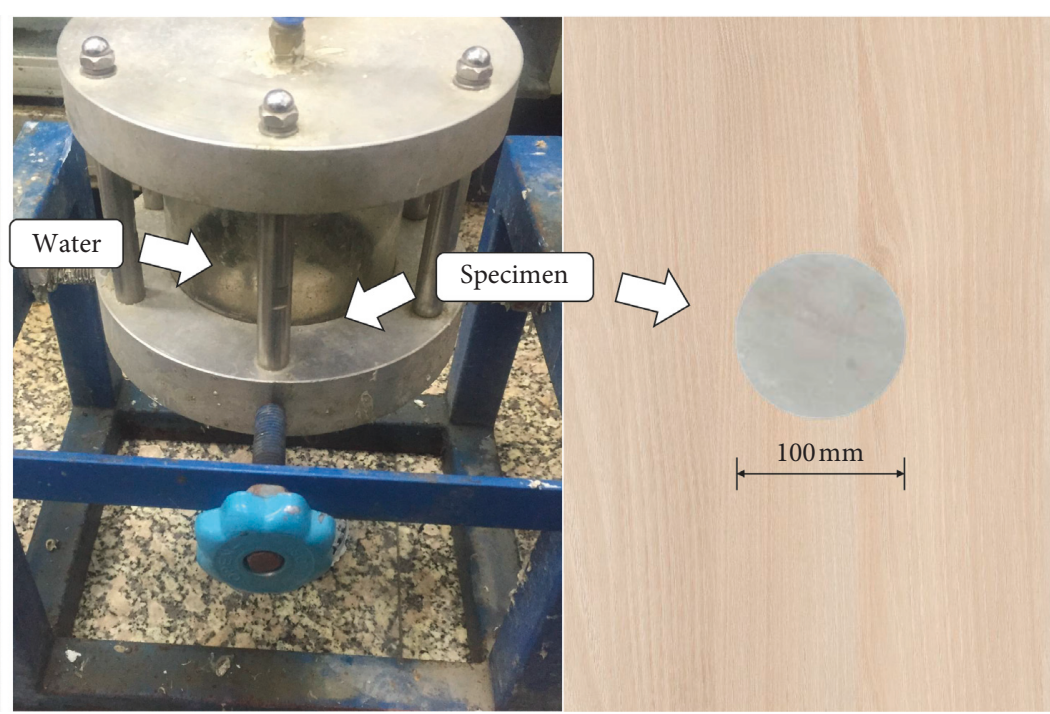

(b) (c)

Figure 2: Permeability test: (a) test system; (b) seepage device; (c) specimen.

2.4. SEM and XRD. SEM is often used to observe the micromorphology. In this study, the cracks of ECC were observed with SEM, as shown in Figure 3. Due to the poor conductivity of the cement-based materials, the test specimens were gold-plated before observation. In addition, the energy dispersive spectrometer (EDS) was used to analyze the types and contents of elements near the crack.

In addition, $\mathrm{XRD}$ was used to conduct the phase analysis of self-healing products. The measurements were conducted using dried powders [29]. The specimens and the equipment used for XRD in this study are shown in Figure 4.

\section{Results and Discussion}

3.1. Effects of MgO and SAP on the Ductility of ECC. High ductility is the most important characteristic of ECC. Therefore, the ductility cannot be reduced significantly while the self-healing property of ECC is improved. To evaluate the effects of $\mathrm{MgO}$ and SAP on the ductility performance of ECC, the uniaxial tensile test was carried out. The typical tensile stress-strain curves for ECC with different mix proportions are shown in Figure 5. As can be seen from the figure, $\mathrm{MgO}$ and SAP do have an impact on the ductility of ECC. The order for ECC with different mix proportions based on ductility was ECC containing SAP (specimen 3), ordinary ECC (specimen 1), ECC containing $\mathrm{MgO}$ and SAP (specimen 4), and ECC containing $\mathrm{MgO}$ (specimen 2).

To facilitate quantitative analysis, the initial cracking strength, ultimate tensile strength, and ultimate tensile strain of ECC are summarized and presented in Figure 6.

The initial cracking strength for ordinary ECC (specimen 1), ECC containing MgO (specimen 2), ECC containing SAP (specimen 3), and ECC containing $\mathrm{MgO}$ and SAP (specimen 4) is $2.38 \mathrm{MPa}, 2.58 \mathrm{MPa}, 2.23 \mathrm{MPa}, 2.43 \mathrm{MPa}$, respectively. Also, the ultimate tensile strain for ordinary ECC (specimen 1), ECC containing MgO (specimen 2), ECC containing SAP (specimen 3), and ECC containing MgO and SAP (specimen 4) is $2.90 \%, 2.53 \%, 3.22 \%, 2.75 \%$, respectively. The above data indicate that the $\mathrm{MgO}$ increases the strength of ECC while SAP decreases the strength of ECC. But, for the ductility of ECC, $\mathrm{MgO}$ reduces the ductility while SAP improves the ductility.

These above changes are directly related to the changes of $\mathrm{MgO}$ and SAP. The hydration of $\mathrm{MgO}$ produces $\mathrm{Mg}(\mathrm{OH})_{2}$, as shown in Figure 7. The formation and growth of $\mathrm{Mg}(\mathrm{OH})_{2}$ crystals will cause expansion and make ECC denser, which is helpful to the strength but not conducive to the ductility. Thus, ECC containing $\mathrm{MgO}$ (specimen 2) has larger strength and smaller deformation than ordinary ECC (specimen 1).

For the SAP, it is not active and cannot hydrate. SAP is added during batching and will initially swell and form gellike structure. The initial swelling is also confined by the mixing and compaction processes. But, when SAP releases water, it will shrink and the honeycomb-like voids are left in the materials, as shown in Figure 8. These voids can be viewed as internal defects of ECC which has correlation with the strength and ductility of ECC [30]. The test results indicated that SAP is helpful to the ductility but leads to decrease in the strength of ECC.

Taken together, the effects of $\mathrm{MgO}$ and SAP used in this study on the ductility property of ECC are balanced. The ECC prepared with $\mathrm{MgO}$ and SAP shows obvious ductility.

3.2. Effects of $M g O$ and SAP on the Self-Healing Property of ECC. The changes of RSR with the number of dry-wet cycles are shown in Figure 9. As can be seen from the figure, the water permeability decreases with the number of curing cycles, initially at a rapid rate and gradually stabilized, which indicated that the self-healing of ECC with different mix proportions does occur. The control ECC specimens without $\mathrm{MgO}$ and SAP (specimen 1) need 10-12 cycles to complete 


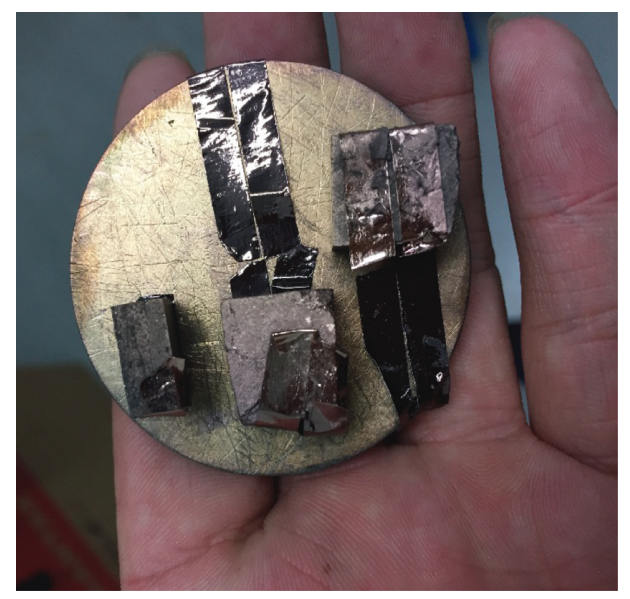

(a)

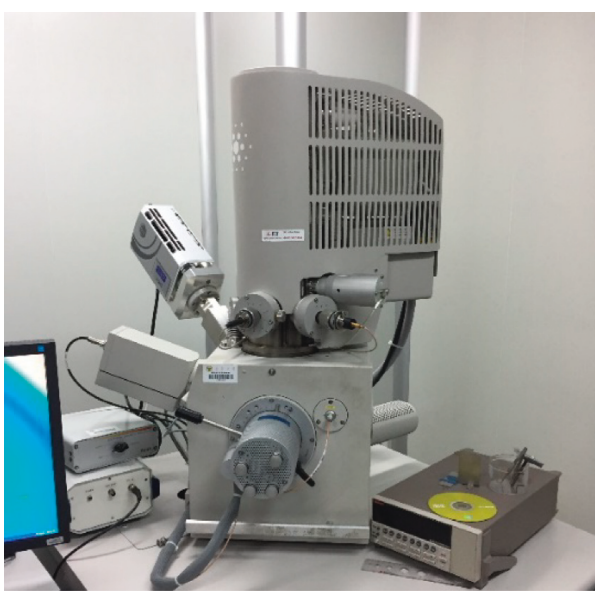

(b)

Figure 3: SEM: (a) specimen after gold plating; (b) equipment.

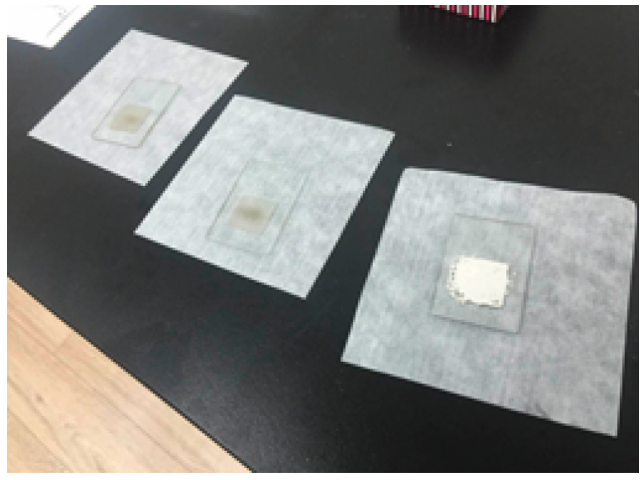

(a)

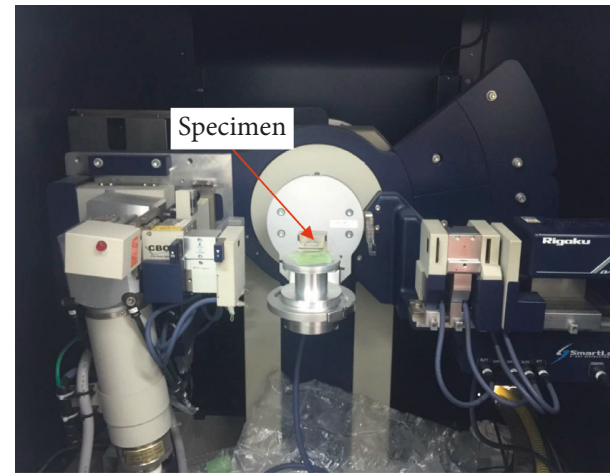

(b)

FIGURE 4: XRD: (a) specimen preparation; (b) equipment.

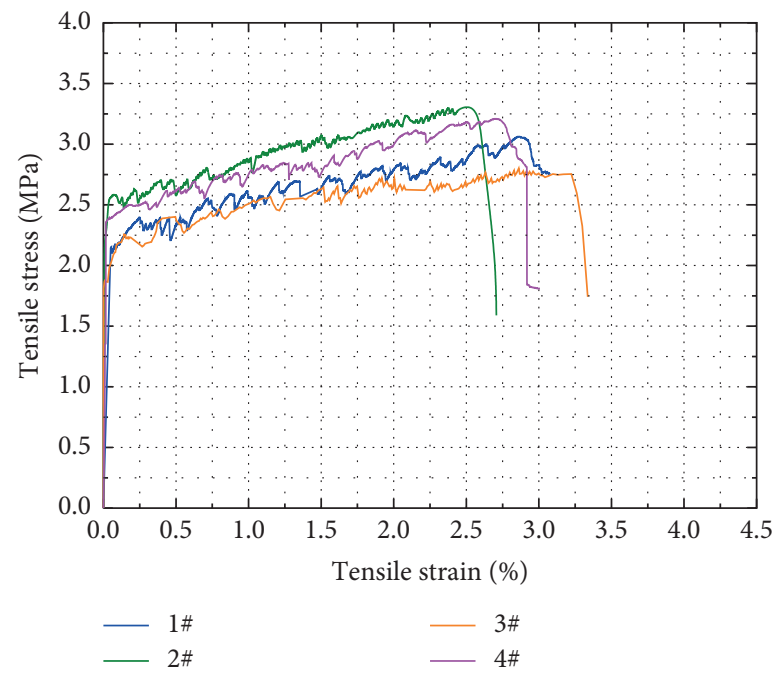

Figure 5: Typical stress-strain curves for ECC with different mix proportions.

the self-healing process; the self-healing of ECC specimens containing MgO (specimen 2) lasts 8-9 cycles; ECC specimens incorporating SAP (specimen 3) needs 7-9 cycles;
ECC specimens incorporating $\mathrm{MgO}$ and SAP (specimen 4) only need 5-6 cycles to complete the self-healing. Therefore, it can be concluded that the individual addition of $\mathrm{MgO}$ or 


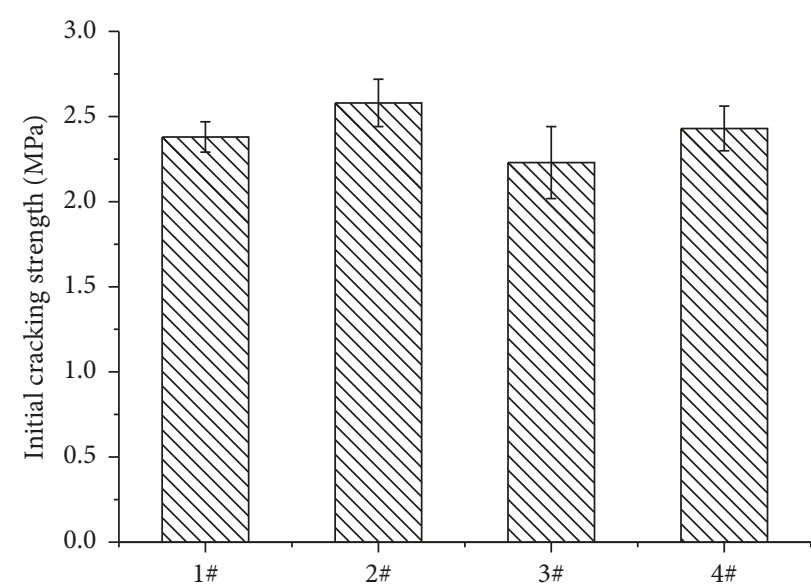

(a)

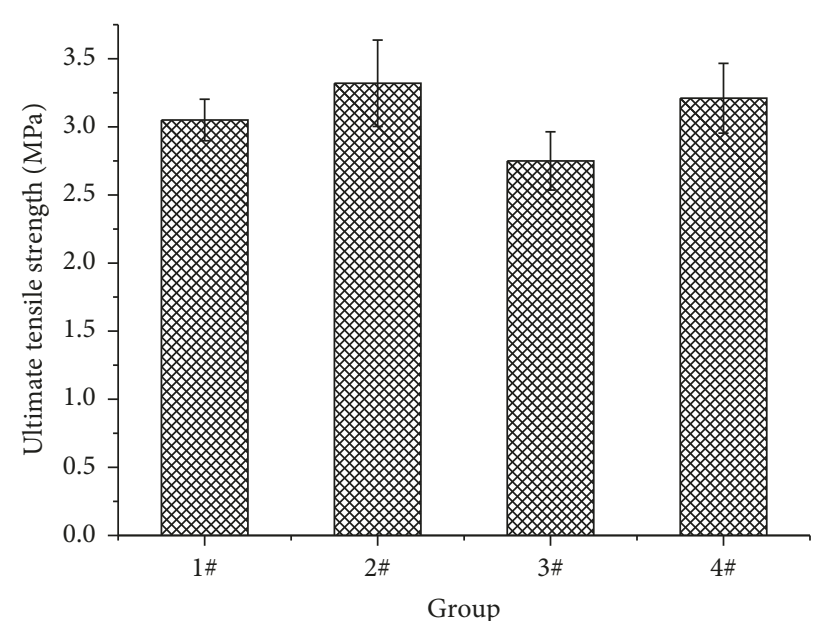

(b)

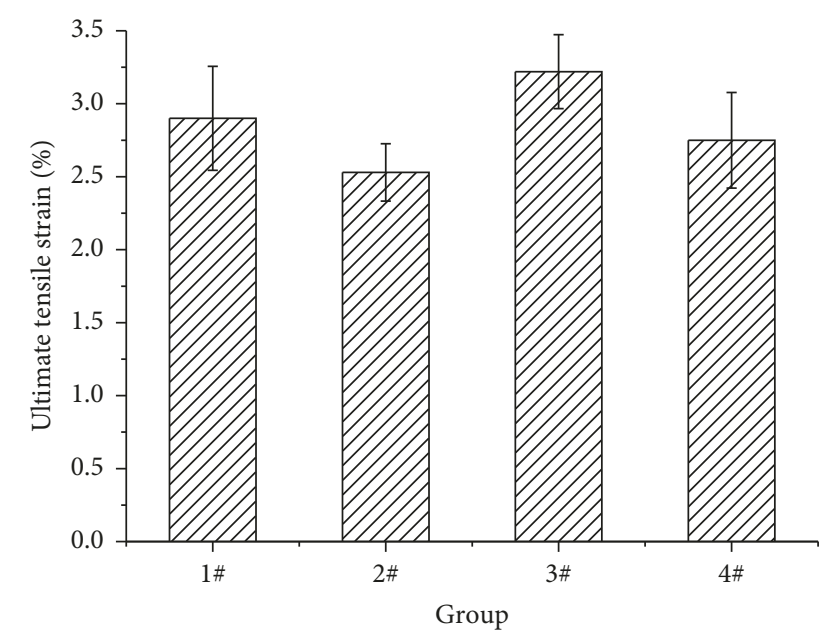

(c)

Figure 6: Results of uniaxial tensile test: (a) initial cracking strength; (b) ultimate tensile strength; (c) ultimate tensile strain.

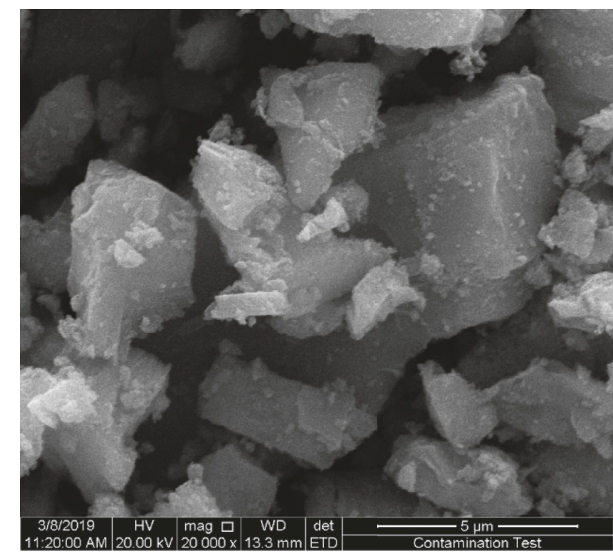

(a)

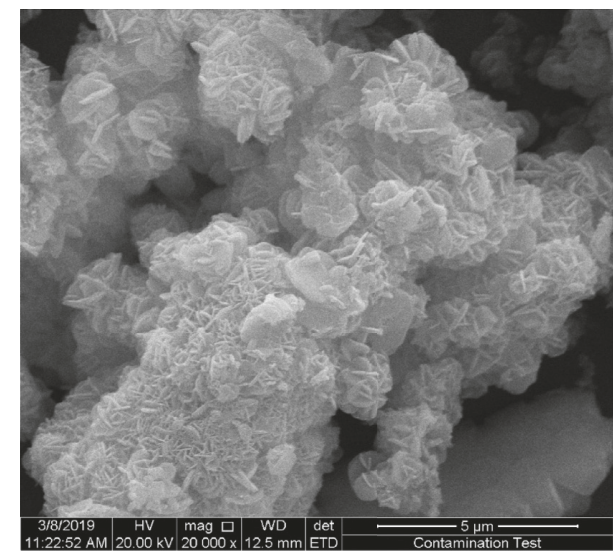

(b)

Figure 7: SEM images of MgO and its hydration products: (a) MgO; (b) hydration products.

SAP is conductive to the self-healing process. The selfhealing of ECC can be improved significantly under the joint action of $\mathrm{MgO}$ and SAP.
Magnesium hydroxide $\left(\mathrm{Mg}(\mathrm{OH})_{2}\right)$ which is the hydration product of $\mathrm{MgO}$ can cause microexpansion during its hydration process $[19,20]$. Both sides of the cracks will be 


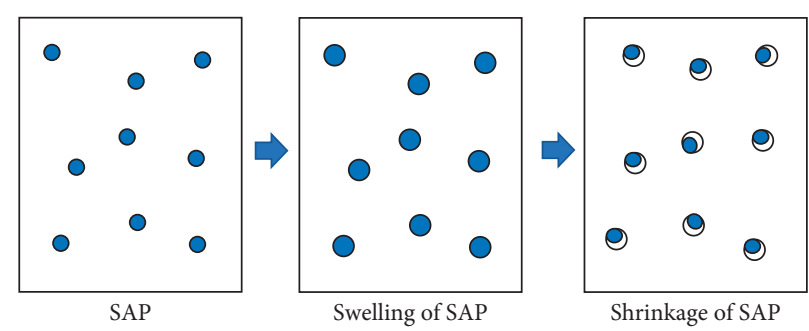

FIGURE 8: Schematic of the swelling and shrinkage of SAP.

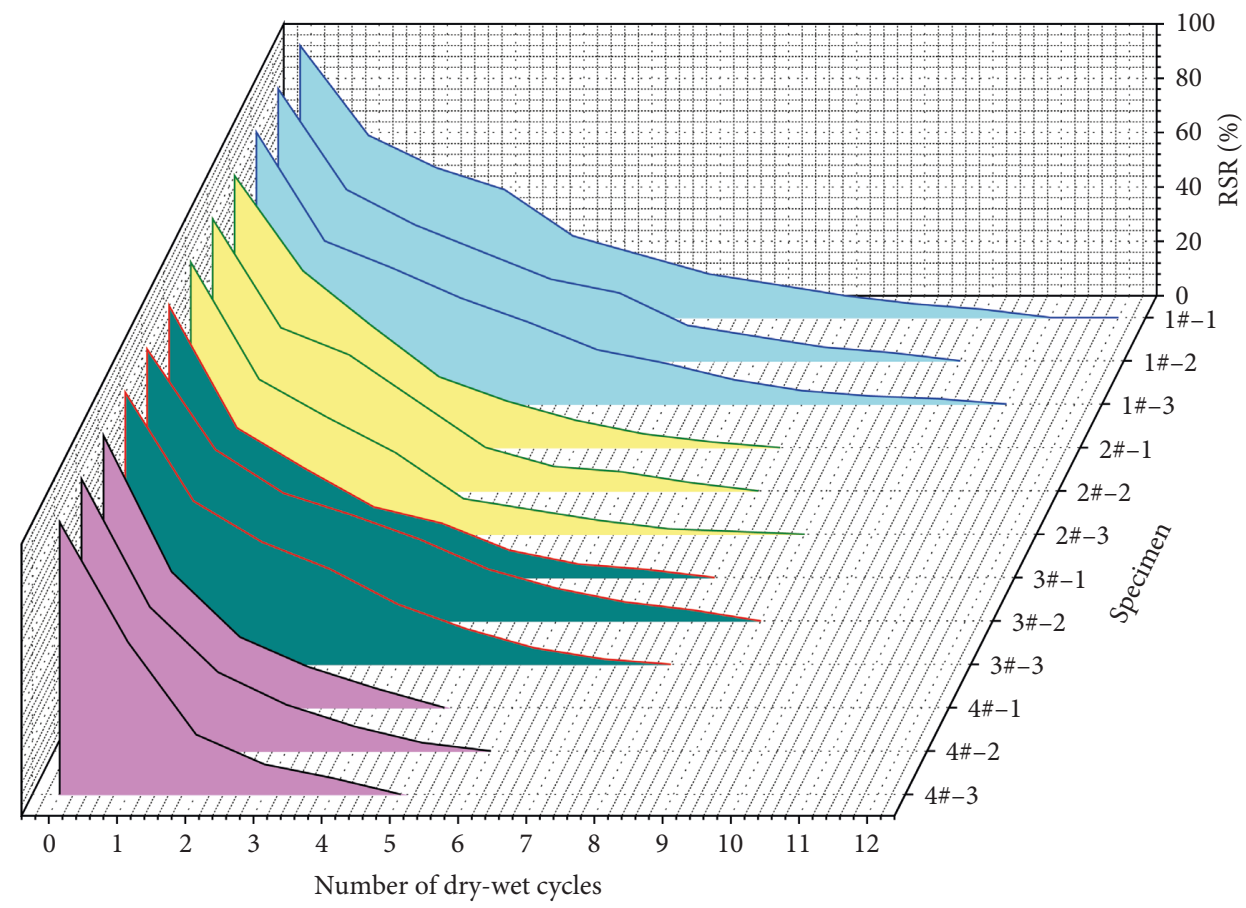

FIGURE 9: Variation of seepage with dry-wet cycles.

squeezed because of the expansion action, and the cracks tend to be closed. The hydration product $\mathrm{Mg}(\mathrm{OH})_{2}$ can also be the filler in the cracks. On the contrary, SAP can store a large amount of water in the form of gel and then slowly releases $[18,22]$. Therefore, under dry conditions, SAP can provide water needed for hydration of $\mathrm{MgO}$ and other cementitious materials and accelerate the formation of hydration products. Under the joint action of $\mathrm{MgO}$ and SAP, the self-healing of ECC will be faster and more effective. The mechanism is illustrated in Figure 10.

Besides, it also can be concluded from the permeability test that both actions of $\mathrm{MgO}$ and SAP can accelerate the self-healing process of ECC, but individual addition of $\mathrm{MgO}$ or SAP cannot realize the fastest healing speed. The combined addition of $\mathrm{MgO}$ and SAP at the same time can cut the healing time by half, which is much better than the individual addition of $\mathrm{MgO}$ or SAP. Therefore, the combination of $\mathrm{MgO}$ and SAP is recommended. $S A P$. Figure 11 shows the self-healing images of the ECC specimen incorporating $\mathrm{MgO}$ and SAP. It can be seen from the figure that the cracks were filled with pale self-healing products.

To microscopically observe and analyze healing products in the cracks, SEM and EDS tests were conducted on selfhealed ECC. The SEM images in Figure 12 also showed that the cracks in ECC were filled up after dry-wet cycles.

From a microscopic perspective, there are multiple chemical reactions in the self-healing process of ECC incorporating $\mathrm{MgO}$ and $\mathrm{SAP}$, and they can be classified as the following: (1) continuous hydration of cementitious materials to form C-S-H; (2) formation of $\mathrm{CaCO}_{3}$; (3) hydration of $\mathrm{MgO}$.

The clinkers in the cement such as $3 \mathrm{CaO} \cdot \mathrm{SiO}_{2}\left(\mathrm{C}_{3} \mathrm{~S}\right)$, $2 \mathrm{CaO} \cdot \mathrm{SiO}_{2}\left(\mathrm{C}_{2} \mathrm{~S}\right)$, $3 \mathrm{CaO} \cdot \mathrm{Al}_{2} \mathrm{O}_{3}\left(\mathrm{C}_{3} \mathrm{~A}\right)$, and $4 \mathrm{CaO} \cdot \mathrm{Al}_{2} \mathrm{O}_{3} \cdot \mathrm{Fe}_{2}$ $\mathrm{O}_{3}\left(\mathrm{C}_{4} \mathrm{AF}\right)$ hydrate as expressed in equations (2) and (3). Active $\mathrm{SiO}_{2}$ and $\mathrm{Al}_{2} \mathrm{O}_{3}$ in fly ash react with calcium hydroxide produced by clinker hydration to form cementitious material, which is called pozzolanic reaction, as shown in equations (4) and (5). At the same time, $\mathrm{Ca}^{2+}$ combines with $\mathrm{CO}_{3}{ }^{2-}$ dissolved in water and forms $\mathrm{CaCO}_{3}$ crystals, as shown in equations (6). Hydration reaction of $\mathrm{MgO}$ shown in equation (7) provides with expansion action. 


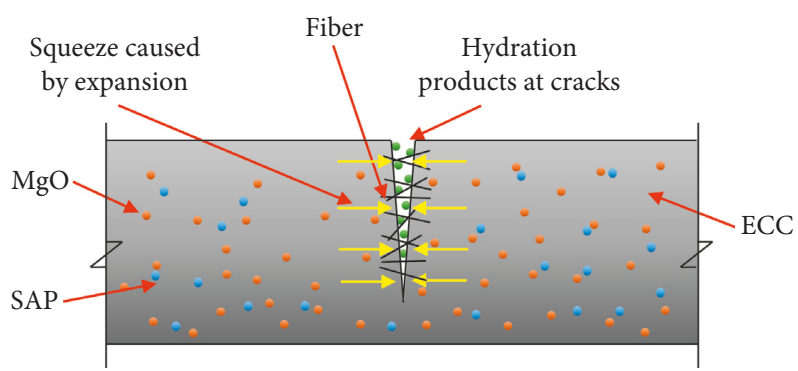

FIgURE 10: Typical load-displacement curves of shear test under different freeze-thaw cycles.

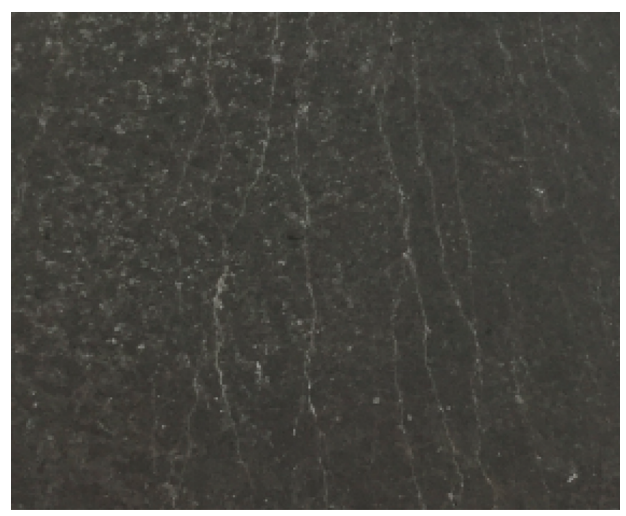

(a)

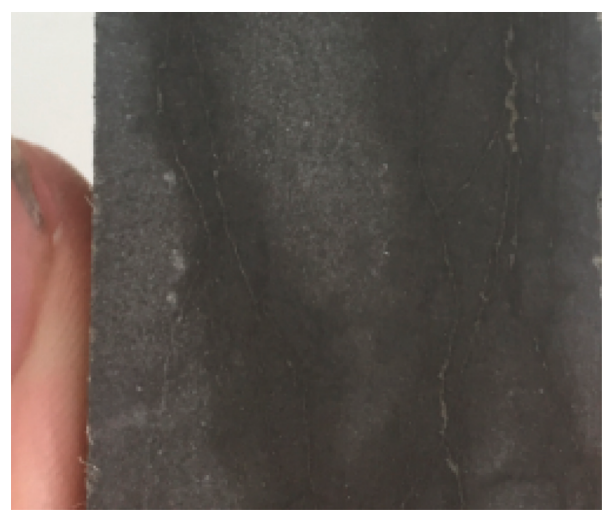

(b)

FIGURE 11: Macroimages of self-healing.

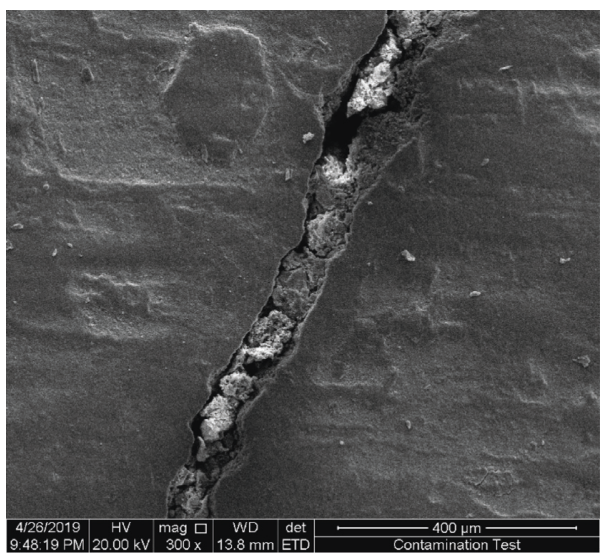

(a)

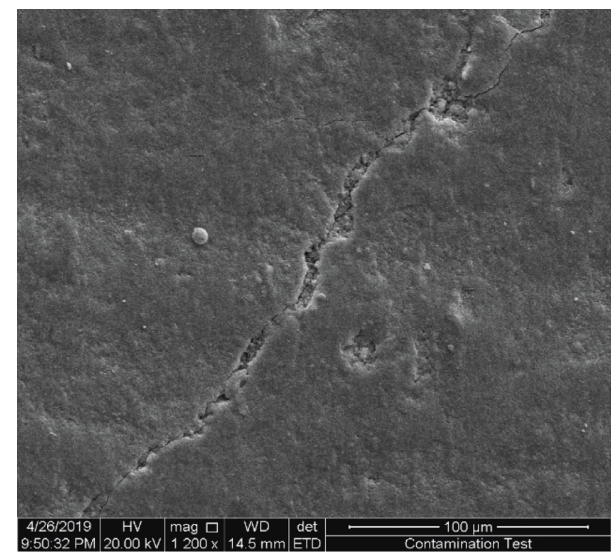

(b)

Figure 12: Microimages of self-healing.

$$
\begin{array}{r}
3 \mathrm{CaO} \cdot \mathrm{SiO}_{2}+n \mathrm{H}_{2} \mathrm{O}=x \mathrm{CaO} \cdot \mathrm{SiO}^{2} \\
\cdot y \mathrm{H}_{2} \mathrm{O}+(3-x) \mathrm{Ca}(\mathrm{OH})_{2} \\
2 \mathrm{CaO} \cdot \mathrm{SiO}_{2}+n \mathrm{H}_{2} \mathrm{O}=x \mathrm{CaO} \cdot \mathrm{SiO}_{2} \\
\cdot y \mathrm{H}_{2} \mathrm{O}+(2-x) \mathrm{Ca}(\mathrm{OH})_{2}
\end{array}
$$

$$
\begin{array}{r}
x \mathrm{Ca}(\mathrm{OH})_{2}+\mathrm{SiO}_{2}+\mathrm{m}_{1} \mathrm{H}_{2} \mathrm{O}=x \mathrm{CaO} \\
\cdot \mathrm{SiO}_{2} \cdot \mathrm{n}_{1} \mathrm{H}_{2} \mathrm{O} \\
x \mathrm{Ca}(\mathrm{OH})_{2}+\mathrm{Al}_{2} \mathrm{O}_{3}+\mathrm{m}_{2} \mathrm{H}_{2} \mathrm{O} \\
=y \mathrm{CaO} \cdot \mathrm{SiO}_{2} \cdot \mathrm{n}_{2} \mathrm{H}_{2} \mathrm{O}
\end{array}
$$



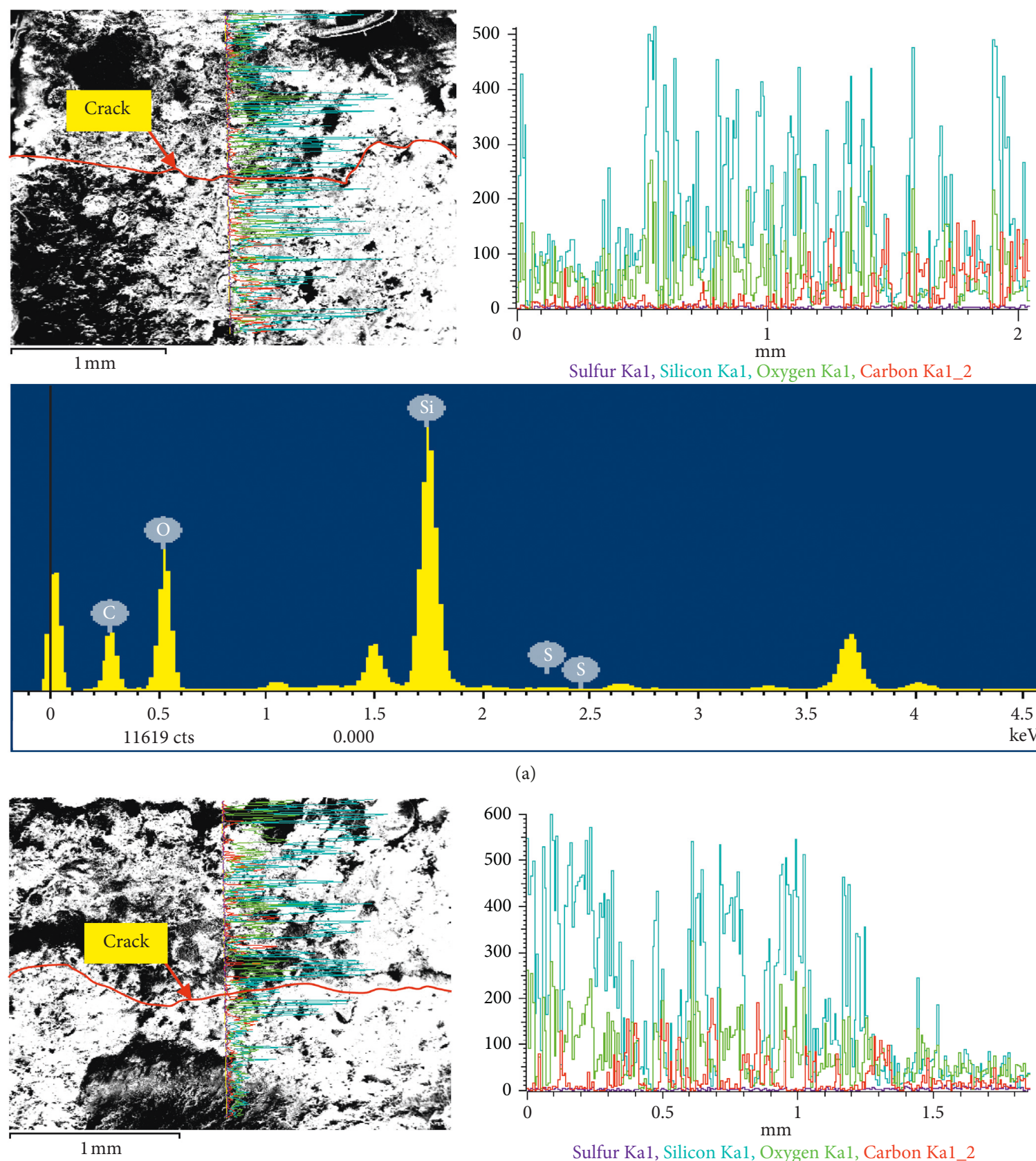

Sulfur Ka1, Silicon Ka1, Oxygen Ka1, Carbon Ka1_2

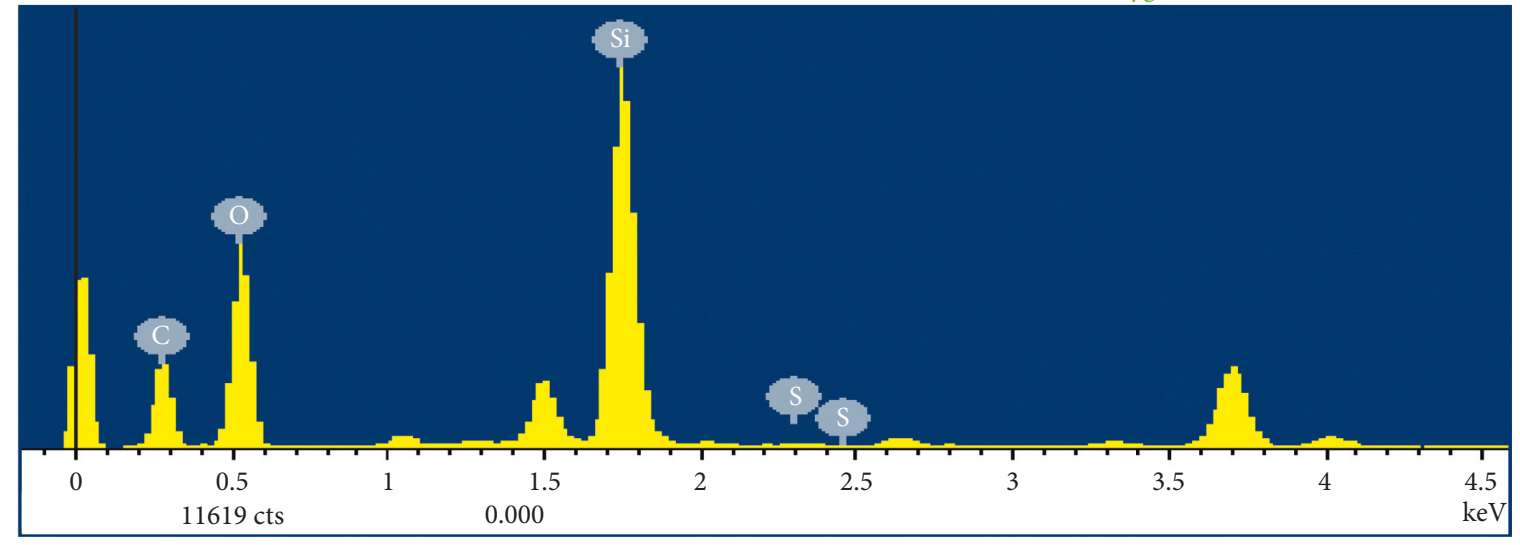

(a)

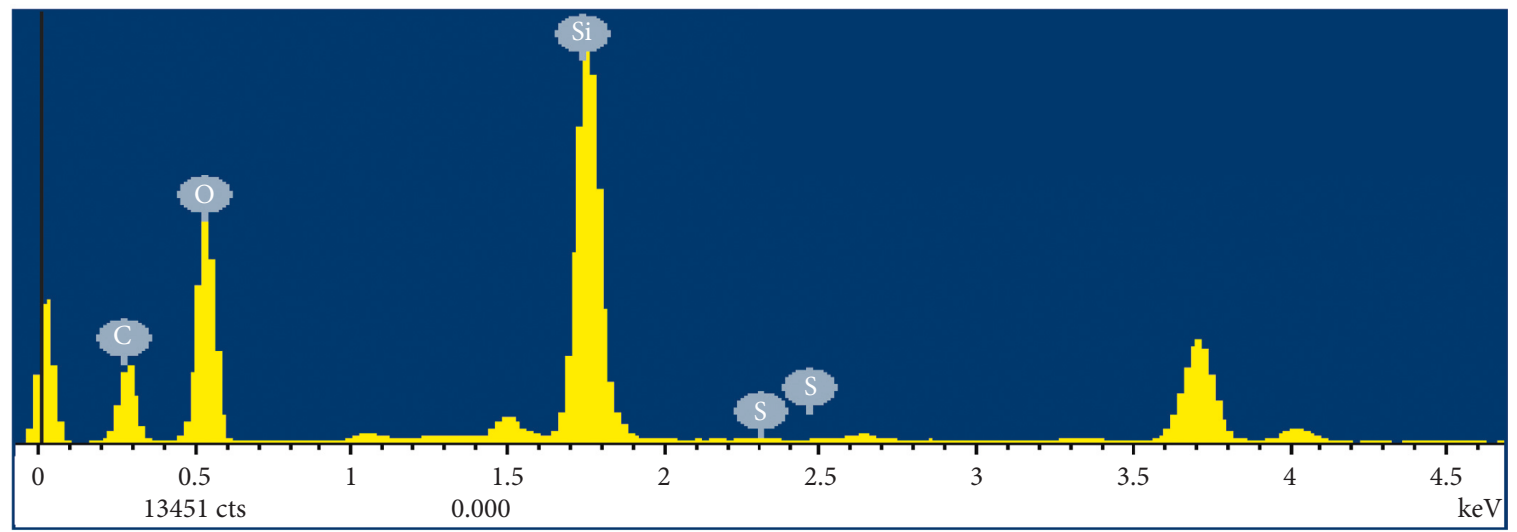

(b)

Figure 13: Continued. 


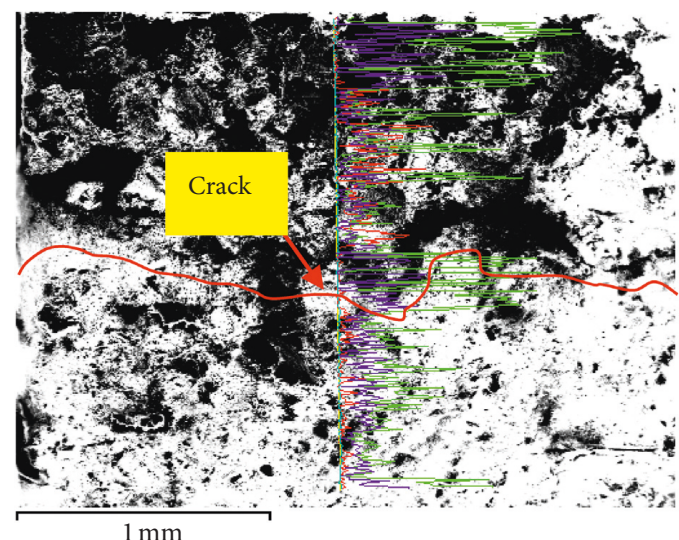

$1 \mathrm{~mm}$

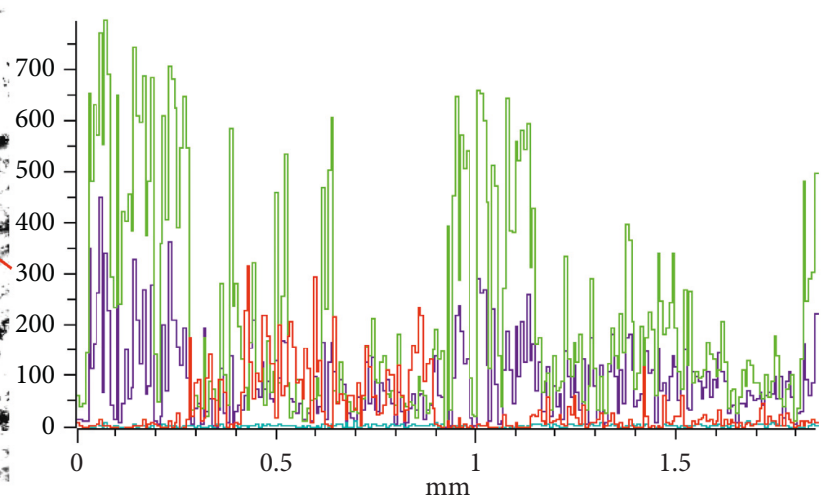

Oxygen Ka1, Sulfur Ka1, Silicon Ka1, Carbon Ka1_2

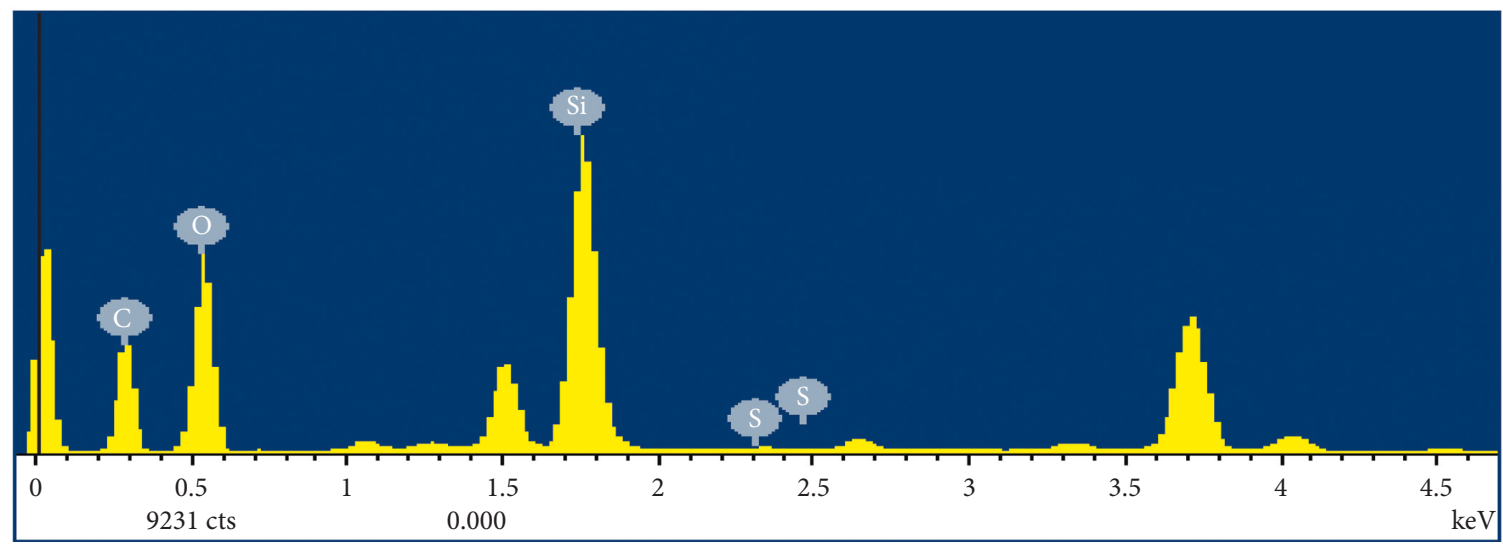

(c)

FIgure 13: EDS analysis for ECC incorporating MgO and SAP.

$$
\begin{aligned}
& \mathrm{Ca}^{2+}+\mathrm{CO}_{3}^{2-}=\mathrm{CaCO}_{3} \\
& \mathrm{MgO}+\mathrm{H}_{2} \mathrm{O}=\mathrm{Mg}(\mathrm{OH})_{2}
\end{aligned}
$$

In addition, under dry conditions, water needed for the hydration of cementitious materials and $\mathrm{MgO}$ can be provided by SAP. Further hydration will continue under dry conditions. All the above reactions and actions work together for ECC incorporating $\mathrm{MgO}$ and SAP and lead to the acceleration of self-healing.

To better understand the mechanism of sealing-healing, it is necessary to analyze the self-healing products. Thus, chemical analysis methods EDS and XRD are used in this study.

First, a straight-line EDS scanning perpendicular to the crack was conducted to detect the changes of main element composition after self-healing. The results along the line crossing the crack for ECC incorporating $\mathrm{MgO}$ and SAP are shown in Figures 13(a)-13(c), which are from different specimens. As can be seen from the figure, after the selfhealing, cracks are closed, and main chemical composition remains consistent with the normal materials.

To analyze the chemical compositions of self-healing products, three different dots in the healed crack were analyzed by EDS for each specimen. Table 6 shows the proportions of the main elements of self-healing products in the self-healed crack of ECC specimens. Data for ECC before self-healing were obtained from the specimen surface near the crack, therefore reflecting the element composition of the original specimen. Based on the table, the proportions of $\mathrm{C}$, which is an element of $\mathrm{CaCO}_{3}$, and $\mathrm{Si}$, which forms C-S$\mathrm{H}$, change significantly after self-healing cycles. The increase in the proportion of $\mathrm{C}$ can be explained that the contents of $\mathrm{CaCO}_{3}$ increase in the healed products of cracks $[18,24]$. But, the change in the amount of C-S-H is difficult to judge only based on the element changes.

To further clarify the hydration products, XRD was used to analyze the self-healing products at the cracks of ECC. The results of XRD for ECC incorporating $\mathrm{MgO}$ and SAP are shown in Figures 14(a) and 14(b), which are two typical types of results. As can be seen form Figure 14(a), the hydration products and calcium carbonate crystals are the main fillers of cracks. In addition, due to that a large amount of fly ash is added in ECC in this study and the hydration of fly ash is slow in the early stage, more hydration products are produced in the later stage and become the self-healing products, so sometimes, XRD results (Figure 14(b)) show $\mathrm{C}-\mathrm{S}-\mathrm{H}$ domains in the self-healing products.

The formation of hydration products is not limited to the early stage because of the addition of fly ash. Also, the literature revealed that the hydration of light-burnt $\mathrm{MgO}$ 
TABLE 6: EDS analysis results of self-healing products.

\begin{tabular}{|c|c|c|c|c|}
\hline \multirow{2}{*}{ Self-healing } & \multicolumn{4}{|c|}{ Element (atom percentage (\%)) } \\
\hline & $\mathrm{C}$ & $\mathrm{O}$ & $\mathrm{Si}$ & $\mathrm{S}$ \\
\hline \multirow{3}{*}{ Before } & 31.92 & 59.69 & 8.32 & 0.06 \\
\hline & 30.76 & 58.52 & 10.65 & 0.06 \\
\hline & 34.88 & 54.65 & 10.45 & 0.02 \\
\hline \multirow{3}{*}{ After } & 44.90 & 54.14 & 0.92 & 0.04 \\
\hline & 42.47 & 56.51 & 0.97 & 0.05 \\
\hline & 44.26 & 54.81 & 0.91 & 0.02 \\
\hline
\end{tabular}

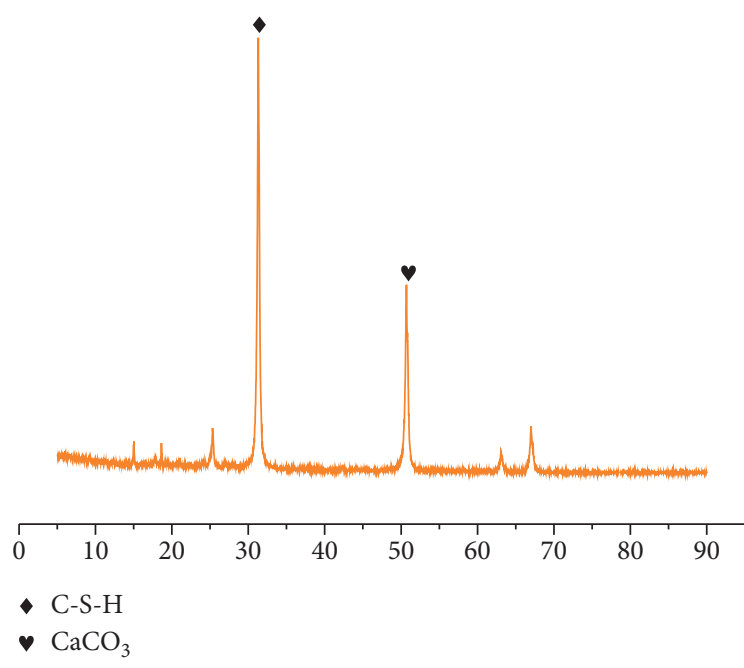

(a)

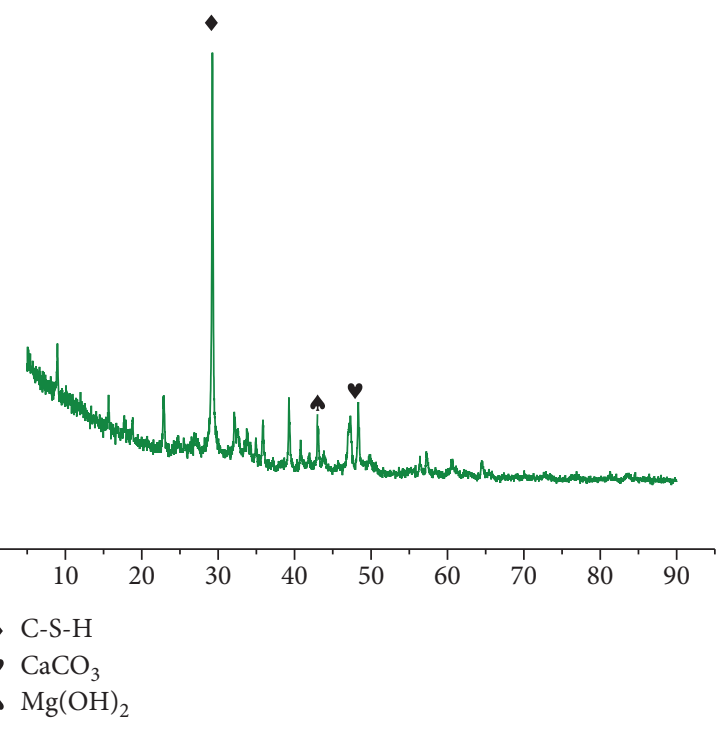

(b)

FIGURE 14: XRD analysis for self-healing products of ECC incorporating MgO and SAP: (a) Major products composed of C-S-H and CaCO ; (b) major products composed of C-S-H.

could provide long-term expansive effect after concrete is hardened (ranging from 7 to 1000 days) [20]. Therefore, the ECC-MgO-SAP system proposed in this study can be considered to be continuous, sustainable, and durable in terms of self-healing.

\section{Conclusions}

In this study, light-burned $\mathrm{MgO}$ and SAP were added in ECC to enhance self-healing properties of ECC. The effects of $\mathrm{MgO}$ and SAP on the ductility performance of ECC were explored with uniaxial tensile test. The permeability test, SEM, and XRD were used to investigate the self-healing properties of ECC. Based on the obtained results, the following conclusions can be drawn:

(1) The hydration of $\mathrm{MgO}$ causes expansion and makes ECC denser, which is helpful to the strength but not conducive to the ductility. SAP cannot hydrate and will produce honeycomb-like voids after release of water. Thus, SAP is helpful to the ductility but leads to decrease in the strength of ECC. The ultimate tensile strain of ECC containing $\mathrm{MgO}$ and SAP prepared in this paper can be as high as $2.75 \%$. The ductility of ECC can be guaranteed by adjusting the ratios of $\mathrm{MgO}$ and SAP.

(2) The expansion induced by the hydration of $\mathrm{MgO}$ makes the cracks close, while SAP provides water for further hydration even under dry conditions. The two actions can both accelerate the self-healing process of ECC. The combined addition of $\mathrm{MgO}$ and SAP can reduce the healing time by about $50 \%$.

\section{Data Availability}

The data used to support the findings of this study are available from the corresponding author upon request.

\section{Conflicts of Interest}

The authors declare no conflicts of interest.

\section{Acknowledgments}

This research was funded by the National Natural Science Foundation of China (nos. 51778140 and 51578290). It was also supported by the Fundamental Research Funds for the Central Universities and Postgraduate Research \& Practice 
Innovation Program of Jiangsu Province (no. KYCX18_0137). Besides, the authors also acknowledge the support of the German Research Foundation (DFG, no. OE 514/1-2, FOR2089). The authors gratefully acknowledge the support of those who provided their generous help during the writing of this paper.

\section{References}

[1] V. C. Li, "From micromechanics to structural engineering-the design of cementitious composites for civil engineering application," Journal of Structural Mechanics and Earthquake Engineering, vol. 10, pp. 37-48, 1993.

[2] B. S. Mohammed, M. F. Nuruddin, M. Aswin, N. Mahamood, and $\mathrm{H}$. Al-Mattarneh, "Structural behavior of reinforced selfcompacted engineered cementitious composite beams," Advances in Materials Science and Engineering, vol. 2016, Article ID 5615124, 12 pages, 2016.

[3] H. Deng, "Utilization of local ingredients for the production of high-early-strength engineered cementitious composites," Advances in Materials Science and Engineering, vol. 2018, Article ID 8159869, 15 pages, 2018.

[4] Y. Zheng, L. F. Zhang, and L. P. Xia, "Investigation of the behaviour of flexible and ductile ECC link slab reinforced with FRP," Construction and Building Materials, vol. 166, pp. 694-711, 2018.

[5] H. Ma, Z. Zhang, B. Ding, and X. Tu, "Investigation on the adhesive characteristics of Engineered Cementitious Composites (ECC) to steel bridge deck," Construction and Building Materials, vol. 191, pp. 679-691, 2018.

[6] Y. Guan, H. Yuan, Z. Ge, Y. Huang, S. Li, and R. Sun, "Flexural properties of ECC-concrete composite beam," Advances in Civil Engineering, vol. 2018, Article ID 3138759, 7 pages, 2018.

[7] L. Xu, J. Pan, and J. Cai, "Seismic performance of precast RC and RC/ECC composite columns with grouted sleeve connections," Engineering Structures, vol. 188, pp. 104-110, 2019.

[8] Y. Li, J. Zhu, and Z. Wang, "Investigation on mechanical properties of masonry infill wall strengthened with ECC," KSCE Journal of Civil Engineering, vol. 23, no. 1, pp. 295-306, 2019.

[9] G. Wang, C. Yang, Y. Pan et al., "Shear behaviors of RC beams externally strengthened with engineered cementitious composite layers," Materials, vol. 12, no. 13, p. 2163, 2019.

[10] E. Herbert and V. Li, "Self-healing of microcracks in engineered cementitious composites (ECC) under a natural environment," Materials, vol. 6, no. 7, pp. 2831-2845, 2013.

[11] H. Huang, G. Ye, D. Damidot, and D. Denis, "Characterization and quantification of self-healing behaviors of microcracks due to further hydration in cement paste," Cement and Concrete Research, vol. 52, pp. 71-81, 2013.

[12] K. R. Lauer and F. Slate, "Autogenous healing of cement paste," ACI Journal Proceedings, vol. 52, no. 6, p. 1083, 1956.

[13] R. K. Dhir, C. M. Sangha, and J. G. Munday, "Strength and deformation properties of autogenously healed mortars," ACI Journal Proceedings, vol. 70, no. 3, p. 231, 1973.

[14] Y. H. Fang, P. B. An, and W. Zhao, "Permeation and dissolution of cracked cement-based materials and their selfhealing," Journal of Portland, vol. 36, no. 4, p. 451, 2008.

[15] C. Edvardsen, "Water permeability and autogenous healing of cracks in concrete," ACI Materials Journal, vol. 96, no. 4, pp. 448-454, 1999.

[16] M. Maalej, T. Hashida, and V. C. Li, "Effect of fiber volume fraction on the off-crack-plane fracture energy in strain hardening engineered cementitious composites," Journal of the American Ceramic Society, vol. 78, no. 12, pp. 3369-3375, 1995.

[17] L. Kan, H. Shi, G. Zhai et al., "Self-healing process and products of engineering cement-based composites," Journal of Tongji University, vol. 39, no. 10, p. 1517, 2011.

[18] H. Deng, "Mechanical property of strain-hardening cementitious composites modified with superabsorbent polymers," Journal of Southeast University (English Edition), vol. 33, pp. 309-315, 2017.

[19] M. A. A. Sherir, K. M. A. Hossain, and M. Lachemi, "Selfhealing and expansion characteristics of cementitious composites with high volume fly ash and MgO-type expansive agent," Construction and Building Materials, vol. 127, pp. 80-92, 2016.

[20] M. A. A. Sherir, K. M. A. Hossain, and M. Lachemi, "The influence of $\mathrm{MgO}$-type expansive agent incorporated in selfhealing system of Engineered Cementitious Composites," Construction and Building Materials, vol. 149, pp. 164-185, 2017.

[21] H. Ma, E. Herbert, M. Ohno, and V. C. Li, "Scale-linking model of self-healing and stiffness recovery in Engineered Cementitious Composites (ECC)," Cement and Concrete Composites, vol. 95, pp. 1-9, 2019.

[22] Y. Shim, G. Hong, and S. Choi, "Autogenous healing of earlyage cementitious materials incorporating superabsorbent polymers exposed to wet/dry cycles," Materials, vol. 11, no. 12, p. 2476, 2018.

[23] S. Mustafa, Y. Gurkan, and K. E. Tahir, "Self-healing capability of cementitious composites incorporating different supplementary cementitious materials," Cement and Concrete Composites, vol. 35, no. 1, pp. 89-101, 2013.

[24] H. Ma, S. Qian, and Z. Zhang, "Effect of self-healing on water permeability and mechanical property of medium-earlystrength Engineered Cementitious Composites," Construction and Building Materials, vol. 68, pp. 92-101, 2014.

[25] Z. Zhang, S. Qian, and H. Ma, "Investigating mechanical properties and self-healing behavior of micro-cracked ECC with different volume of fly ash," Construction and Building Materials, vol. 52, no. 2, pp. 17-23, 2014.

[26] A. Peled, M. F. Cyr, and S. P. Shah, "High content of fly ash (class F) in extruded cementitious composites," ACI Material Journal, vol. 97, no. 5, pp. 509-517, 2000.

[27] C. Redon, V. C. Li, C. Wu, H. Hoshiro, T. Saito, and A. Ogawa, "Measuring and modifying interface properties of PVA fibers in ECC matrix," Journal of Materials in Civil Engineering, vol. 13, no. 6, pp. 399-406, 2001.

[28] E. H. Yang, Y. Z. Yang, and V. C. Li, "Use of high volumes of fly ash to improve ECC mechanical properties and material greenness," ACI Materials Journal, vol. 104, no. 6, pp. 620628, 2007.

[29] Z. Sun, X. Lin, P. Liu, D. Wang, A. Vollpracht, and M. Oeser, "Study of alkali activated slag as alternative pavement binder," Construction and Building Materials, vol. 186, pp. 626-634, 2018.

[30] C. Lu, V. C. Li, and C. K. Y. Leung, "Flaw characterization and correlation with cracking strength in engineered cementitious composites (ECC)," Cement and Concrete Research, vol. 107, pp. 64-74, 2018. 


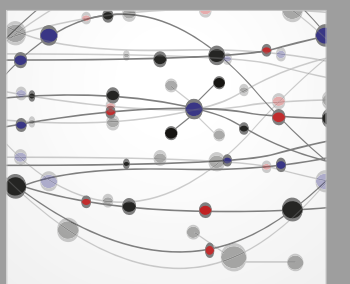

The Scientific World Journal
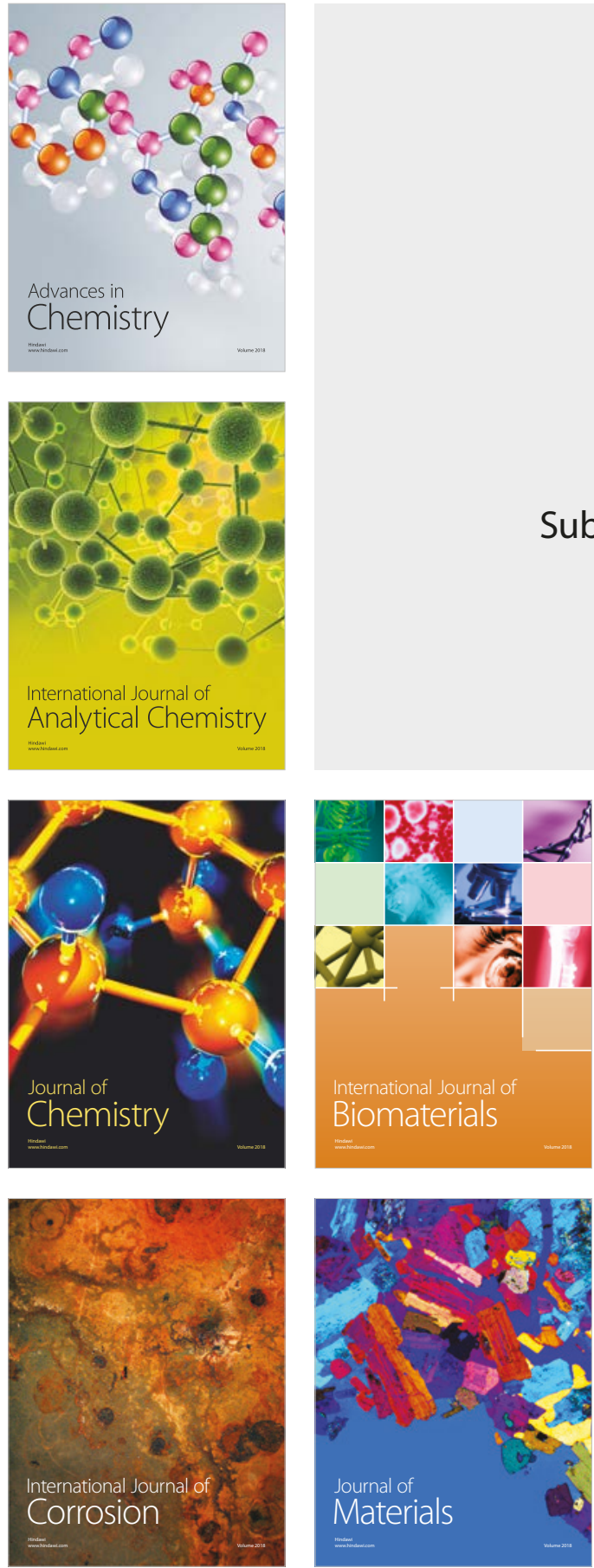

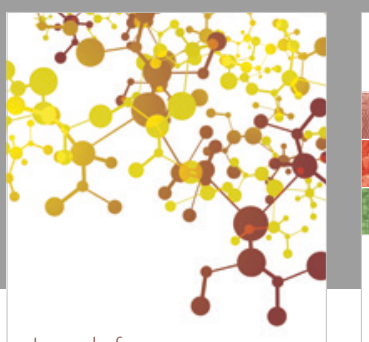

Journal of

Applied Chemistry
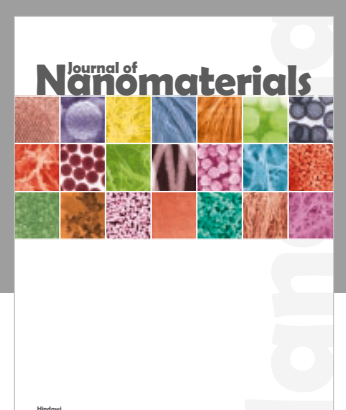

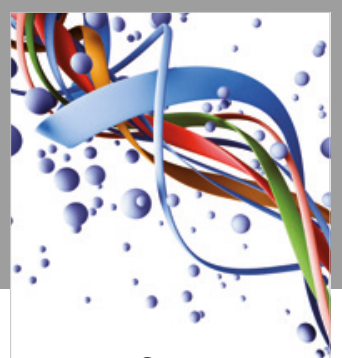

Scientifica

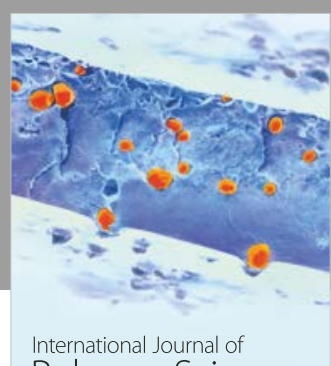

Polymer Science

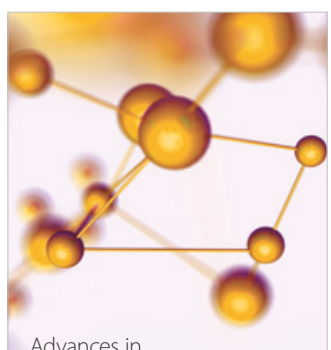

Physical Chemistry
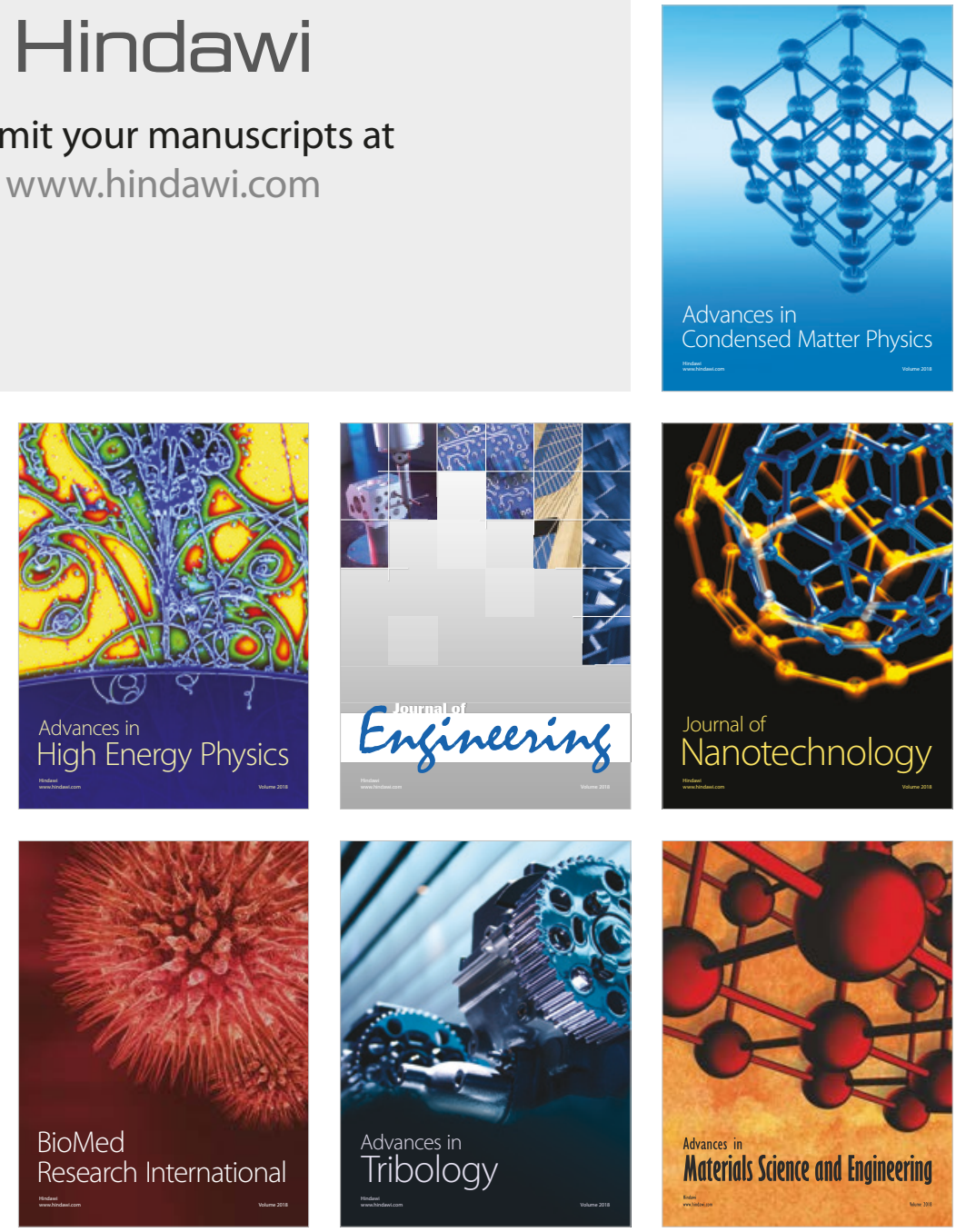